\title{
STORM WATER FLOOD MODELING IN URBAN AREAS
}

\author{
Y.R. Satyaji Rao ${ }^{1}$, R.Venkata Ramana ${ }^{2}$ \\ ${ }^{I}$ Deltaic Regional Cenre, National Institute of Hydrology Kakinada, Andhra Pradesh \\ ${ }^{2}$ Deltaic Regional Cenre, National Institute of Hydrology Kakinada, Andhra Pradesh \\ yrsrao@nih.ernet.in
}

\begin{abstract}
Storm water flood simulations were attempted through the existing drainage networks of Patna and Chennai urban areas using Storm Water Management Model (SWMM). The input for the model was extracted from different sources and maps in GIS environment. The existing drainage networks catchments were delineated using the Digital Elevation Model (DEM) and flow direction in drainage network. The simulation results are calibrated with observed hydrograph peaks and shape of the hydrographs. The model was run considering the original designed dimensions of the drainage network without any blockage still it is not adequate to dispose of the runoff for two years return period rainfall in both urban areas.
\end{abstract}

Keywords: Rainfall, Intensity, Infiltration, Catchments, Flooding and Inadequate

\section{INTRODUCTION}

Skyscrapers, paved roads, storm water drains, sewer drains illuminated light system etc. are the symbol of urban areas. The civil engineering structures change the urban area into paradise only if all structures function well throughout the year. During rainy seasons, urban areas are subjected to flooding due to non-provision of storm water drains which convey storm water safely to outfalls. If the water stagnates then there is a likelihood of spreading water borne diseases, which may affect the health of the people. In order to overcome the inundation, the storm water drainage system has to be properly designed. Manual design of storm water drain is a tedious process and takes much time. Hence software accounting for the various aspects of flow processes is required. With the development and growing urbanization, the frequency of urban flooding is continuously increasing. The causes of flooding are mainly due to private dwelling and encroachments on drainage paths. Engineering measures and research towards urban flood control have made great progresses in recent years. Simulation through modeling of urban floods is thus necessary to understand the problems in the drainage system and also to estimate the extent of flooding. Several mathematical models are widely used to model the dynamics of rainfall-runoff and flood generation process.

Hellweger and Madidment (1999) developed an integrated application for delineating drainage basins and determining surface runoff in natural watershed using the HEC-HMS (Hydrology Engineering Center-Hydrologic Modeling System). Application of GIS in urban storm water system was limited because of the need for large, expensive and detailed spatial and temporal databases (Heaney et al. 1999a). Refsgaard et al., (1995) describe the evolution of the Danish Hydraulic Institute's (DHI) land process hydrologic model SHE (System Hydrology European) and its extensive use of GIS. Hellweger and Ferdi (1996) developed an ArcView (GIS) application using the Avenue scripting language to perform the calculation of an SCSbased model, TR-55.

Effective Urban storm water management is highly dependent on appropriate consideration of the spatial variability of urban watershed characteristics. This realization has prompted increasing use of physical based urban watershed models such as the Environmental Protection Agency Storm Water Management model EPASWMM (Huber et al., 1992). Catchment information was constructed in an ARC/INFO data base and transformation developed using this information to generate the input information necessary for operation of a SWMM-based catchment modeling system to simulate surface runoff (Choi et al, .2002). Hsu et al., (2000) developed an urban inundation model, combining a storm sewer model SWMM, two-dimensional (2D) diffusive overland-flow model and operations of pumping stations to simulate inundation in urban areas caused by the surcharge of storm sewers and outlet pumping stations. Karla and Malik (2014) have used storm-CAD software for evaluating existing storm water drainage network in the Chandigarh, India and found that the computed average runoff coefficient from the model is in good agreement with the rational method runoff coefficient, which was adopted for the study region. Lei et al (2015) have used SWMM model for simulating urban flooding of Dongguan city, China found that 1-year return period precipitation, the studied area will have no flooding, but $2,5,10$ and 25 years return period precipitation the studied area will be inundated. It also stated that due to lack of surface runoff routing in the model, the urban flooding could not be forecast precisely. In this paper an attempt has been made to analyze and quantify the extent of urban flooding in Patna and Chennai urban areas using SWMM.

\section{METHODOLOGY}

SWMM model is designed to simulate the runoff of a drainage basin for any pre-described rainfall pattern. Total watershed is broken into a finite number of smaller units or 
sub-catchments that can be readily described by their hydraulic or geometrical properties. Model has mainly three blocks first one is Runoff block, second is Transport block and third is Extran block. The Runoff block uses Manning's equation to route the uniform rainfall intensity over the overland flow surface and flow receives the drains. Transport block determine the quality and quantity of flow and calculate the system infiltration. Extran block is completes the hydraulic calculations for overland flows, in channels, and in pipes. It performs dynamic wave routing and provides all the depth, velocity and energy grade line information

In the first step the study area was divided into subcatchments. The delineations were based upon the topography of the study area, utilizing Digital Elevation Model (DEM), following existing drainage system and present land use pattern. Secondly, infiltration losses were calculated by the inbuilt model in SWMM by using SCS curve number method. Soil Conservation Service suggested an empirical model for rainfall abstractions which is based on the potential for the soil to absorb a certain amount of moisture. On the basis of field observations, this potential storage $\mathrm{S}(\mathrm{mm})$ was related to a 'curve number' $C N$ which is a characteristic of the soil type, land use and the initial degree of saturation known as the antecedent moisture condition. The value of $S$ is defined by the following empirical expression.

$S=\frac{25400}{C N}-254$

$(\mathrm{mm})$

The effective rainfall is computed by the equation:

$Q(t)=\frac{\left(P(t)-I_{a}\right)^{2}}{\left(P(t)+S-I_{a}\right)}$

Where, $Q(t)$ = accumulated depth of effective rainfall in time $\mathrm{t}, \mathrm{P}(t)=$ accumulated depth of rainfall in time $\mathrm{t}$, $I_{a}=$ initial abstraction, $S=$ potential storage in the soil.

The original SCS method assumed the value of the initial abstraction $I_{a}$ to be equal to $20 \%$ of the storage potential S.

$I_{a}=0.2 S$

$Q(t)=\frac{(P(t)-0.2 S)^{2}}{P(t)+0.8 S}$

\section{MODEL CALIBRATION}

Calibration is the process of running a model using a set of input data and comparing the model results to actual measurements of the system. The calibration procedure takes into consideration the peak rate of the event as well as the shape of the hydrograph. After the model is calibrated to a specific storm, it is validated by simulating one or more additional storms and comparing modeled and measured results. Initial calibration efforts showed that the model over-predicted due to conservative estimates of imperviousness or contributing area of the drainage basins. Thus, a detailed GIS analysis and field investigation was undertaken to determine the effective impervious area. The field investigation produced accurate delineation of drainage boundaries.

The objective of the application of a catchment model system is generally to determine peak flow rate and hydrograph shape. The evaluation criteria of relative error (RE) and root mean square error (RMSE) have been used to compare the simulated model output with the observed data. Relative error (RE) for an arbitrary variable $x$

$$
R E=\frac{x_{o}-x_{s}}{x_{o}}
$$

where $x_{o}$ is observed value of a hydrograph characteristic and $x_{s}$ is the simulated value of the same characteristic.

Root mean square error (RMSE) for discharge

$$
R M S E=\sqrt{\frac{\sum_{i=1}^{n}\left[Q_{o}(i)-Q_{s}(i)\right]^{2}}{n}}
$$

where $Q_{s}(i)$ and $Q_{o}(i)$ are the simulated and observed discharges, respectively, and, $n$ is number of observations in the time series.

\section{PATNA CASE STUDY}

The Patna town is situated between the river Ganga in the north, river Punpun in the south and river Sone in the west. The Patna town is an urban residential community with medium density. The area is very flat, with elevation ranging from $47.23 \mathrm{~m}$ to $51.92 \mathrm{~m}$ with mean elevation of $49.68 \mathrm{~m}$. The runoff curve number in SCS model is assigned based on land use class, treatment and soil type. Land use classification of Patna town was performed using IRS-P6 L4MX-PAN data and classified in seven classes. Patna town is a low lying area and the dominant soil type is silty loam to clay. The average saturated hydraulic conductivity of the clay soils has been taken as $0.254 \mathrm{~mm} / \mathrm{h}$. After calibration, the model was run and simulated the peak flow. The measured and simulated values of peak flow have been compared (Table 1). It is found that percentage errors at the four sites range from -0.90 to -6.20 . The negative sign indicates that the simulated value overestimates the observed peak flow. RMSE criteria also imply that the prediction errors are well balanced. Comparison has been made between simulated and measured hydrographs (Figs. 1 to 4$)$.

Table 1: Calibration of the model results with volume and peak flow

\begin{tabular}{|l|l|c|c|c|c|}
\hline S1 & $\begin{array}{c}\text { Name } \\
\text { of the } \\
\text { outfall }\end{array}$ & $\begin{array}{c}\text { Observed } \\
\text { peak } \\
\text { flow } \\
\left(\mathrm{m}^{3} / \mathrm{sec}\right)\end{array}$ & $\begin{array}{c}\text { Simulated } \\
\text { peak flow } \\
\left(\mathrm{m}^{3} / \mathrm{sec}\right)\end{array}$ & RE (\%) & RMSE \\
\hline 1 & Krjee & 4.99 & 5.3 & -6.20 & 0.96 \\
\hline 2 & Rajpurl & 17.36 & 18.04 & -3.90 & 0.94 \\
\hline 3 & Mandiri & 1.11 & 1.12 & -0.90 & 0.97 \\
\hline 4 & Phadi & 18.65 & 19.13 & -2.40 & 0.96 \\
\hline
\end{tabular}




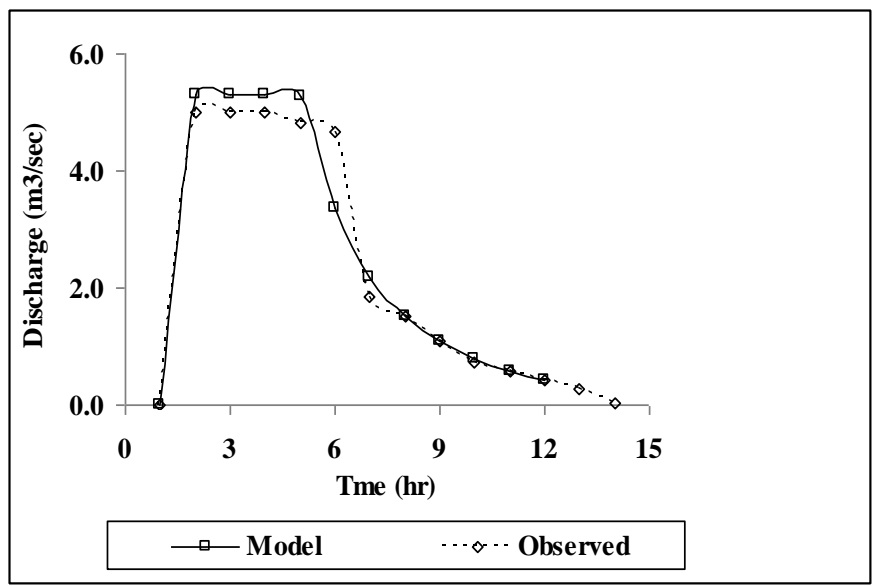

Fig 1.Calibration for Kurjee outfall hydrograph

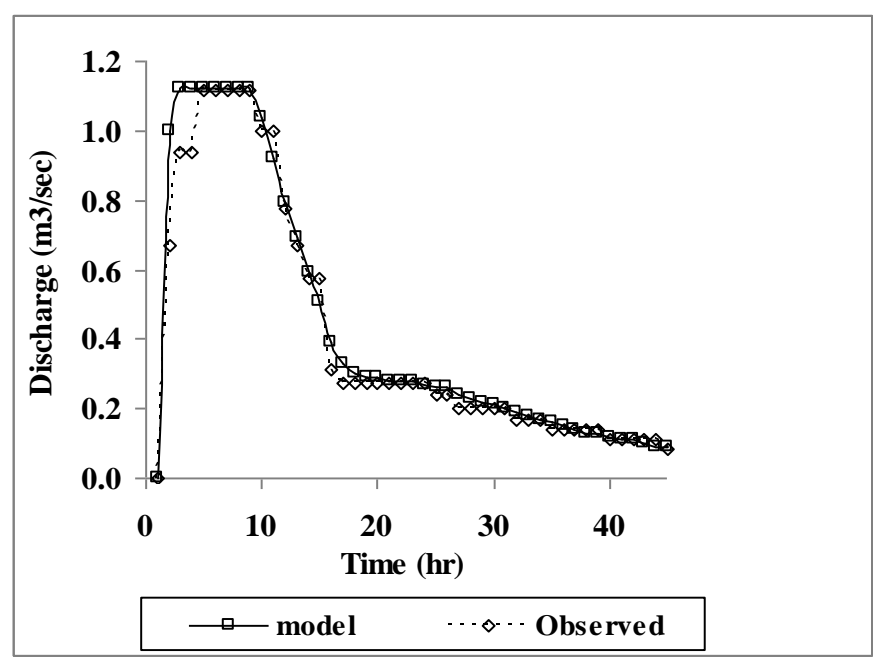

Fig 3. Calibration for Mandiri outfall hydrograph

\section{CHENNAI CASE STUDY:}

The storm water drainage network in the Otteri Naullah sub basin has been studied in the Chennai. Historical hourly rainfall data (1980-2009) nearby locality at Nungambakkam (maintained by IMD) was collected and analyzed. The hourly rainfall computed for $2,5,10$, and 25 years return periods using Extreme Value Type 1 distribution are 48.89, 64.10, 74.08, and $87.24 \mathrm{~mm}$ respectively. Further, DGPS survey was conducted to substantiate spot heights from SOI maps to prepare Digital Elevation Model (DEM) for the study area. The land use/land cover map was prepared using IRS P6 satellite data. The storm water drainage network details and Otteri Nullah longitudinal profiles/cross section details at every $30 \mathrm{~m}$ were collected and GIS database was prepared. Using thematic layers of DEM, drainage network and road network, total 88 micro watersheds were delineated in the Otteri Nullah sub-basin. Model parameters like Node/link characteristics, pervious/impervious area, soil

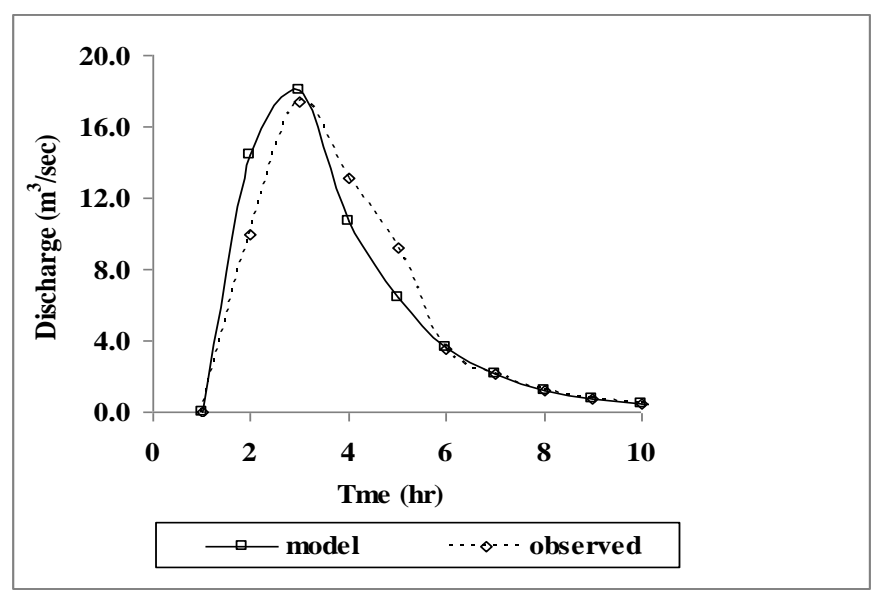

Fig 2. Calibration for Rajapur phool outfall hydrograph

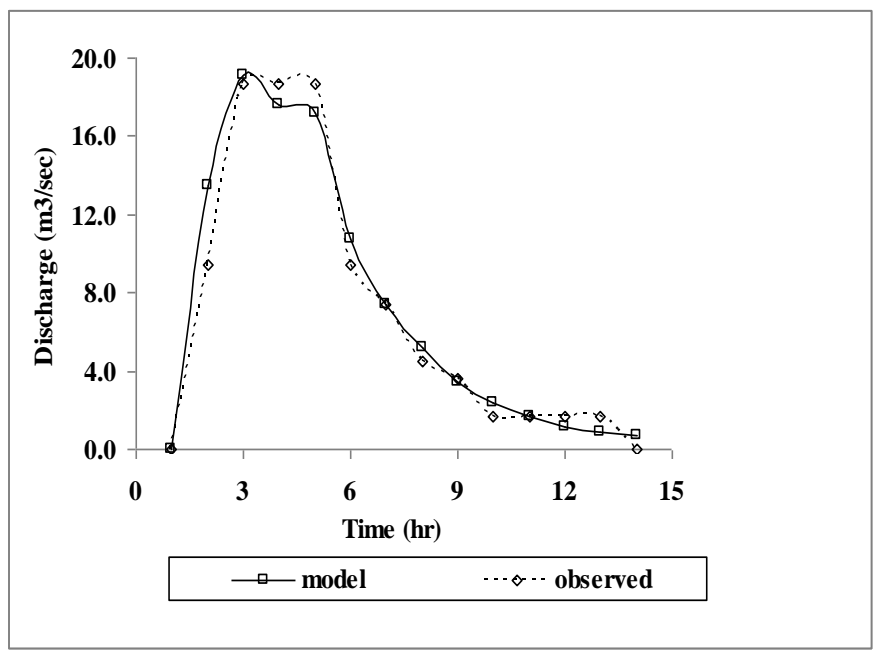

Fig 4. Calibration for Pahadi outfall hydrograph

type, average width/slope and SCS-CN were computed for each micro watershed using GIS data base. Based on observed rainfall and water level data in the study area, few events were selected to analyze the performance of XPSWMM model in terms of runoff computation in the study area (Figure 5). After successful testing of the model, the 24 hrs design storm for 2, 510 and 25 yrs return periods were considered to check the storm water drainage network efficiency in the study area. It was found that the present storm drainage network is not sufficient to drain storm water runoff even for two-year return period storm with existing longitudinal profile of Otteri Nullah. The hydrographs at outfall of the sub basin was developed for design storms of various return periods which would be useful to adopt best management practices (BMP). 


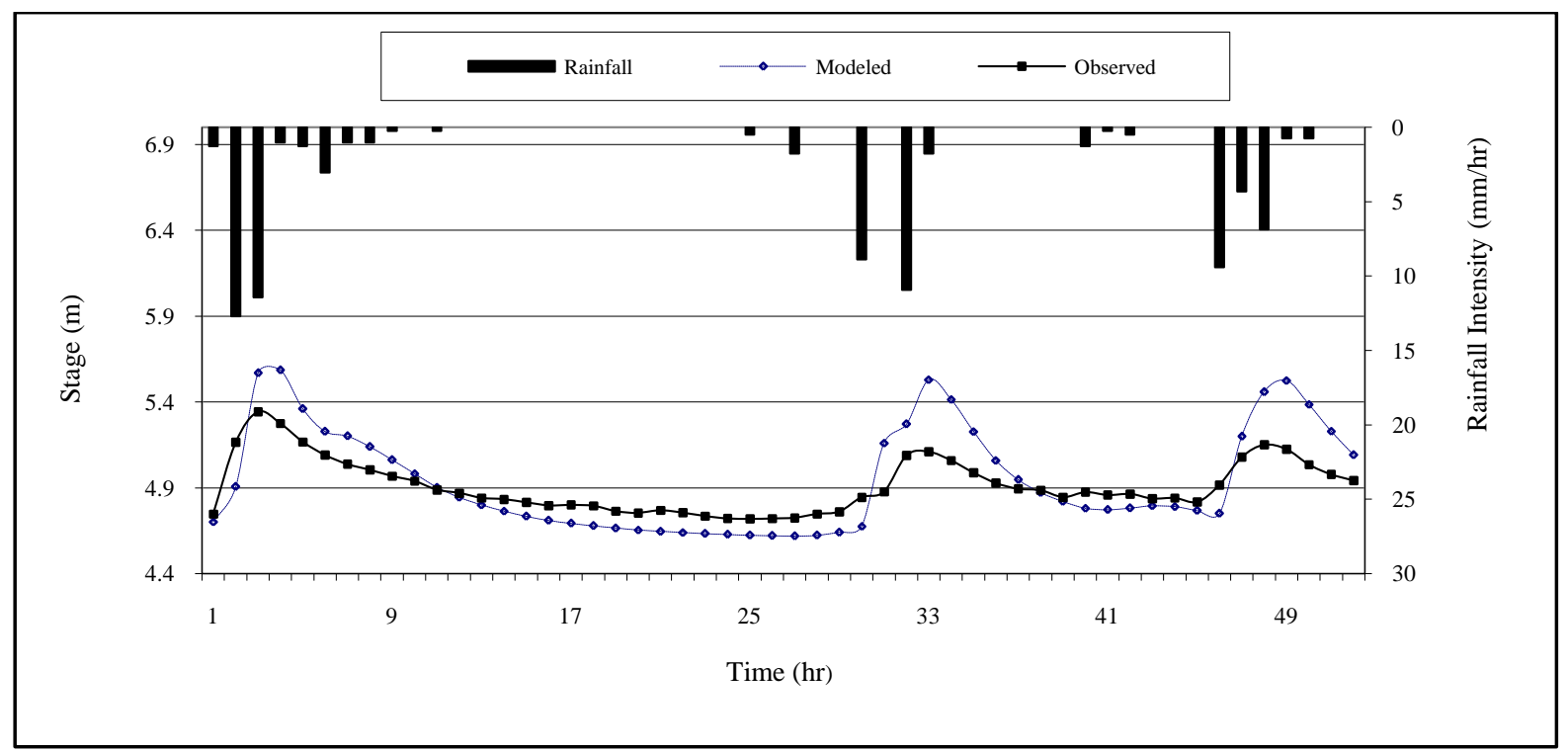

Figure 5. Comparison between observed and simulated stage at Anna Nagar

(25-10-2011, 9.00 to $27-10-2011,12.00)$

\section{CONCLUSION}

The SWMM model was run considering the original designed dimensions of the drainage networks without any blockage. The existing drainage networks of Patna and Chennai urban areas are not even able to dispose of the rainfall depth of 2 year return period. Micro level drainage system is very poor and at many locations there is no connectivity to the macro level drainage system. Maintenance of the conveyance system is also very poor and people are less concern about the health of the system. The drains are chocked due to throwing of garbage and polythene bags, wastages of vegetable, fish markets etc. directly into it. Thus people need be awakened and attention should be given for renovation of the existing drains. Existing design drainage network simulate the runoff for various design storms and prepared the surface inundation maps. This is very useful information and recommended for Best Management Practice (BMP) for design of sumps or ponds and also to decide pump capacity.

\section{REFERENCE}

[1] Choi, K. S. (2001). Doctoral Dissertation. School of Civil and Environmental Engineering, The University of New South Wales, Sydney, Australia.

[2] Heaney, J.P., Sample, D., and Wright, L. (1999a). Geographical Information Systems and Urban Stormwater Management, Draft report to the US EPA, Edison, NJ.

[3] Hellweger and Ferdi (1996). "TABHYD - TR55 Tabular Hydrograph Method in Arc View" U.S. Department of Agriculture, Soil Conservation Service, Engineering Division, September 1996.
[4] Hellweger. F., and Maidment, D. (1999). "Definition and connection of hydrologic element using geograph data.” J. Hydrology Engrg., ASCE, 4(1), 10-18.

[5] Huber, W. C., and Dickinson, W. T. (1992). "Storm Water Management Model, Version 4,User's Manual." EPA-600-3-88-001a, US. Environmental Protection Agency, Athens, GA.

[6] Karla, A.M and Uma Malik (2014). "Assessment of Current Storm water Infrastructure System in Lieu of Flood Points of Interest within Union Territory, Chandigarh". Published in Proceedings of International Symposium on Integrated Water Management (IWRM14) held at CWRDM, Kozhikode, Kerala, India during 19-21, 2014, Volume I, pp.188-194.

[7] Lei Jiang, Yangbo Chen and Huanyu Wang (2015). "Urban flood simulation based on the SWMM model". Published in Proceedings of Remote Sensing and GIS for Hydrology and Water Resources, ICGRHWE14, IAHS Publication, 368, pp.186-191.

[8] Refsgaard, J. C., Storm, B., and Refsgaard, A. (1995). "Recent development of the system hydrologique european (SHE) towards the MIKE SHE." Modelling and management of sustainable basin-scale water resource system. Report to the US EPA, Edison, NJ. 